\title{
Experimental investigations of thermal performance improvement of aluminum ceiling panel for heating and cooling by covering its surface with paint
}

\author{
Eukasz Amanowicz ${ }^{1, *}$, and Janusz Wojtkowiak ${ }^{1}$ \\ ${ }^{1}$ Poznan University of Technology, Institute of Environmental Engineering, ul. Berdychowo 4, \\ 61-131 Poznan, Poland
}

\begin{abstract}
Due to the low emissivity of raw metal surface (i.e. aluminum), the specific heating or cooling performance of non-painted surfaces is powered mainly on the natural convection and is relatively small. It can be sufficient for low energy buildings but not for the traditional ones. To increase the heat exchange through the radiation one can cover the raw surface with paint to increase its emissivity. To investigate the influence of paint cover on the heating and cooling performance of the ceiling-oriented flat aluminum surface the experimental investigations were done. The experiment was conducted on the aluminum ceiling panel with heat exchange surface of the dimensions $0.32 \times 3.0 \mathrm{~m}$. Heating performance of painted surface increased from 2.3 to 2.8 times and cooling performance increased from 1.5 to 1.7 times in the comparison to the non-painted one.
\end{abstract}

\section{Introduction}

Low energy buildings are characterized by the relatively low energy consumption in the comparison to the traditional ones. The main factors that make it possible to achieve the low energy standard are insulation and high air-tightness combined with the use of mechanical ventilation systems with heat recovery [1] supported by an earth-to-air ground heat exchanger $[2,3]$. The specific demand for heating power in such buildings is lower than $15-20 \mathrm{~W} / \mathrm{m}^{2}$, what makes it possible to use the low temperature heating devices, especially surface heating. It is desirable due to the possibility of achieving a higher sense of thermal comfort. The most popular surface heating system is the floor heating, rarely used for the cooling purposes. Another devices that can be used are the ceiling panels that can be made for example of aluminum. Due to the low temperature of their surface these devices can be used comfortably both for heating and cooling. The raw aluminum emissivity is very low $(\varepsilon=0.05-0.1)$ so the heat exchange through the radiation is negligible in the comparison to the natural convection which is the dominant force of the heat exchange. Because of that the heating and cooling performance of devices made of raw aluminum is relatively low what was presented in the article [4]. To enhance the better heat exchange through the radiation it is possible to cover

${ }^{*}$ Corresponding author: lukasz.amanowicz@put.poznan.pl 
the surface with paint what improves its emissivity and increases the heating and cooling performance (the emissivity of black paint $\varepsilon=0.95$ ). In this paper the experimental investigation results are presented showing the influence of covering with paint the aluminum surface of ceiling panel and quantifying the possibility of improving the heat exchange efficiency.

\section{Experimental investigations}

\subsection{Scope of the experiment}

Thermal performance was measured for a ceiling-oriented metal surface shown in Fig. 1. The heat transfer surface has a dimensions: $0.32 \times 3.0 \mathrm{~m}\left(0.96 \mathrm{~m}^{2}\right)$. Near the surface there are water channels which provides hot or cold water for heating or cooling. Thanks to the good thermal properties of metals, the temperature distribution at the surface was almost uniform.

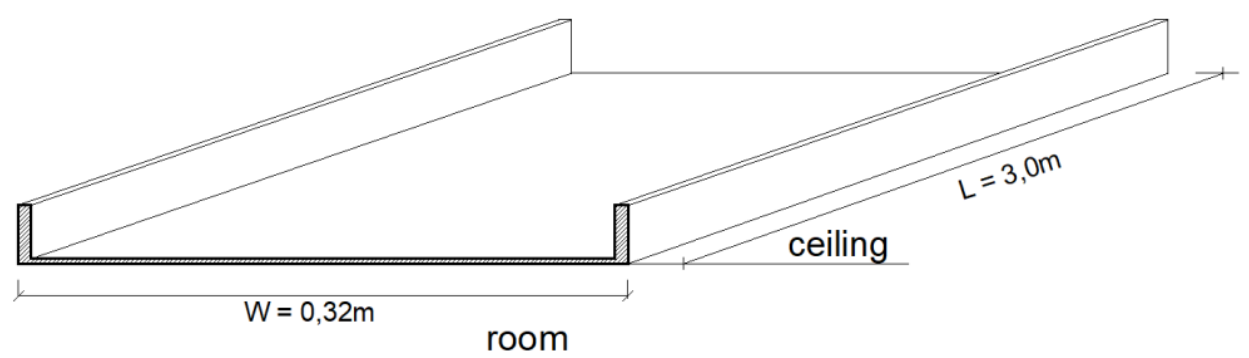

Fig. 1. Schema of the investigated surface.

Thermal performance was investigated for raw metal surface and surface covered with black paint. The cooling performance was investigated for surface temperature: $15.7-27.2^{\circ} \mathrm{C}$ and the laboratory air temperature $26.6-30.3^{\circ} \mathrm{C}$.

The heating performance was investigated for surface temperature: $30.2-50.4^{\circ} \mathrm{C}$ and the laboratory air temperature $23.1-24.5^{\circ} \mathrm{C}$.

\subsection{Experimental set-up}

The schema of the experimental set-up is shown in Fig. 2. For the adiabatic conditions, ceiling side of the surface was insulated with $15 \mathrm{~cm}$ of styrofoam $(\lambda=0.038 \mathrm{~W} / \mathrm{m} / \mathrm{K})$. All water channels was supplied with hot or cold water from the ultra-thermostat. The uniform water division between all water channels was assured by the main pipes (manifolds) having much more bigger diameters than the channels diameter $d_{\text {main }} \gg d$ what was investigated experimentally in [2,5-11] (investigations of airflow division in multi-pipe earth-to-air heat exchangers). The water flow was measured using weight method. The view of the experimental set-up is shown in the Fig. 3. 


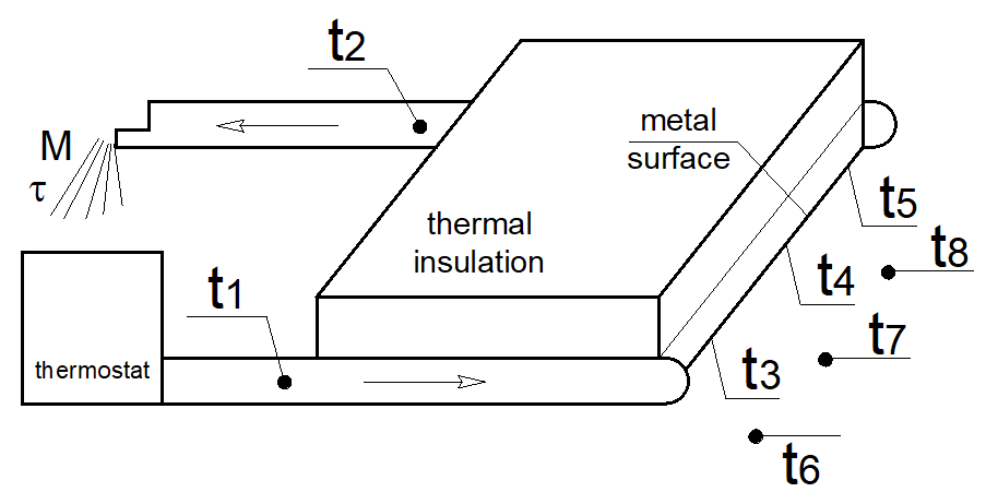

Fig. 2. Schema of the experimental set-up.

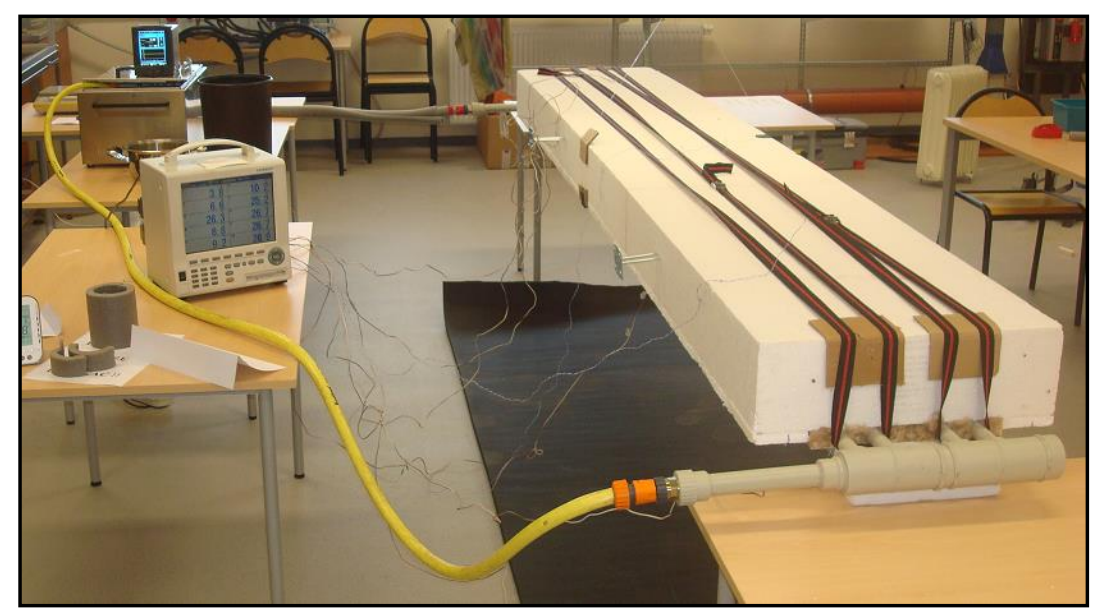

Fig. 3. View of the experimental set-up.

\subsection{Measured and calculated values}

The measured values are given in the Table 1 . The calculated values are given in the Table 2.

Table 1. Measured values.

\begin{tabular}{|c|c|}
\hline Symbol & Description \\
\hline$t_{1}\left[{ }^{\circ} \mathrm{C}\right]$ & water temperature at the inlet \\
\hline$t_{2}\left[{ }^{\circ} \mathrm{C}\right]$ & water temperature at the outlet \\
\hline$t_{3}, t_{4}, t_{5},\left[{ }^{\circ} \mathrm{C}\right]$ & temperature of the panel surface \\
\hline$t_{6}, t_{7}, t_{8}\left[{ }^{\circ} \mathrm{C}\right]$ & air temperature \\
\hline$M[\mathrm{~kg}]$ & mass of the water \\
\hline$\tau[\mathrm{s}]$ & time of gathering the water \\
\hline
\end{tabular}


Table 2. Calculated values.

\begin{tabular}{|c|c|}
\hline Symbol & Description \\
\hline$m[\mathrm{~kg} / \mathrm{s}]$ & mass flowrate \\
\hline$\Delta t_{1-2}[\mathrm{~K}]$ & water temperature change in the panel \\
\hline$Q[\mathrm{~W}]$ & thermal power of the panel \\
\hline$\alpha\left[\mathrm{W} /\left(\mathrm{m}^{2} \mathrm{~K}\right)\right]$ & total heat transfer coefficient \\
\hline$q\left[\mathrm{~W} / \mathrm{m}^{2}\right]$ & specific thermal power of the panel \\
\hline
\end{tabular}

The thermal power of the surface was calculated as:

$$
Q=m \times c_{\mathrm{w}} \times \Delta t_{1-2}
$$

The specific thermal power of the surface was calculated as:

$$
q=Q / A
$$

$A$ - the heat exchange area, $\left[\mathrm{m}^{2}\right]$

The water mass flowrate was calculated as:

$$
m=M / \tau
$$

The temperature difference was calculated as:

$$
\Delta t_{1-2}=t_{2}-t_{1}
$$

The total heat transfer (convection and radiation) coefficient was calculated as:

$$
\alpha=Q /\left[A \times\left(t_{\mathrm{w}, \mathrm{av}}-t_{\mathrm{a}, \mathrm{av}}\right)\right]
$$

$t_{\mathrm{w}, \mathrm{m}}$ - average temperature of the surface, $\left[{ }^{\circ} \mathrm{C}\right]$

$t_{\mathrm{a}, \mathrm{m}}$ - average temperature of the air in the laboratory, $\left[{ }^{\circ} \mathrm{C}\right]$

$$
\begin{aligned}
& t_{\mathrm{w}, \mathrm{av}}=\left(t_{3}+t_{4}+t_{5}\right) / 3 \\
& t_{\mathrm{a}, \mathrm{av}}=\left(t_{6}+t_{7}+t_{8}\right) / 3
\end{aligned}
$$

\subsection{Apparatus and accuracy}

Temperature of water and air was measured with calibrated $\mathrm{Cu}-\mathrm{Konstantan}$ thermocouple sensors, cooperating with multichannel temperature meter with accuracy of $\pm 0.1^{\circ} \mathrm{C}$.

The water mass was measured using an electronic laboratory scale with accuracy of $\pm 0.1 \mathrm{~g}= \pm 0.0001 \mathrm{~kg}$ with accuracy of $\pm 0.2 \%$.

Measurement of the filling time of the measuring vessel was done with an electronic stopwatch with accuracy of $\pm 0.01 \mathrm{~s}$.

Accuracy of water flowrate measurement was estimated to be $\pm 0.5 \%$ (taking into account the influence of all interfering factors and including stopwatch and weight synchronization).

The water temperature was stabilized with the ultra-thermostat with the accuracy of $\pm 0.02 \mathrm{~K}$. 


\section{Results}

The results are presented in the Figs. 4-7. It can been seen that both total heat transfer coefficient $\alpha$ and specific heating or cooling performance of the painted and non-painted surface increase as the temperature difference between the surface and air increases. The total heat transfer coefficient of the painted surface for cooling drastically decreases when the temperature difference is lower than $8-9 \mathrm{~K}$ what can be seen in the Fig. 5.

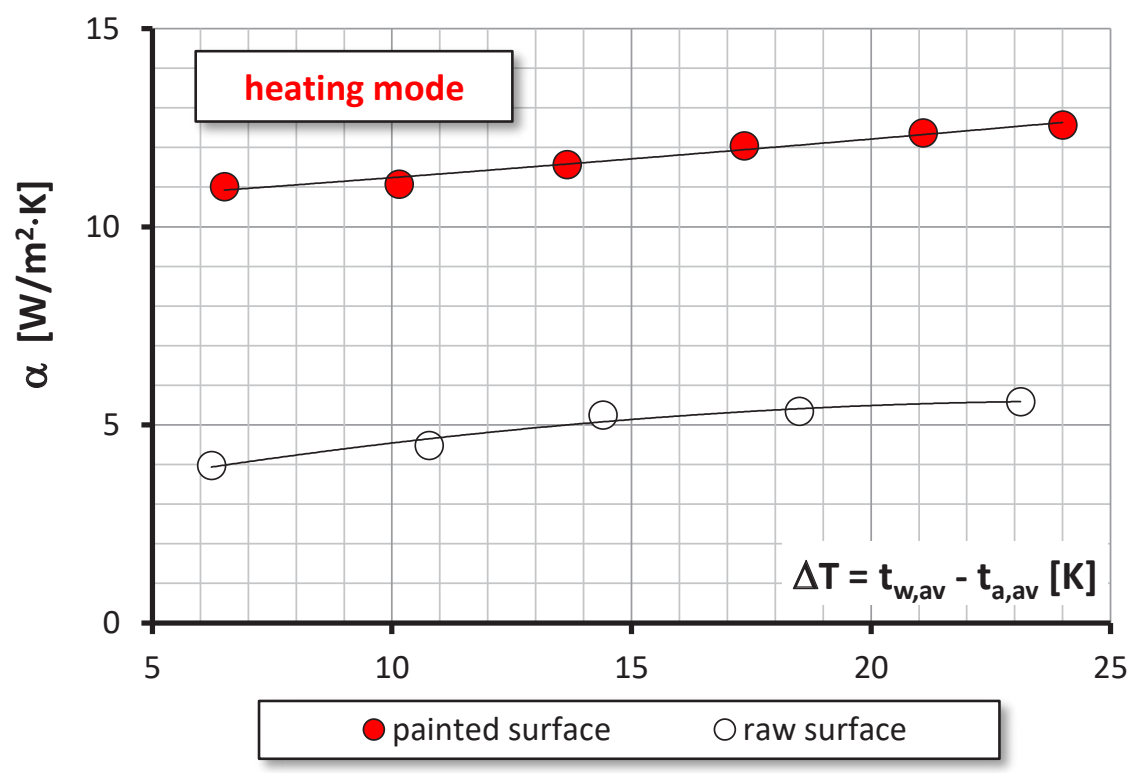

Fig. 4. The total heat transfer coefficient for heating mode as a function of the temperature difference between surface and air. 


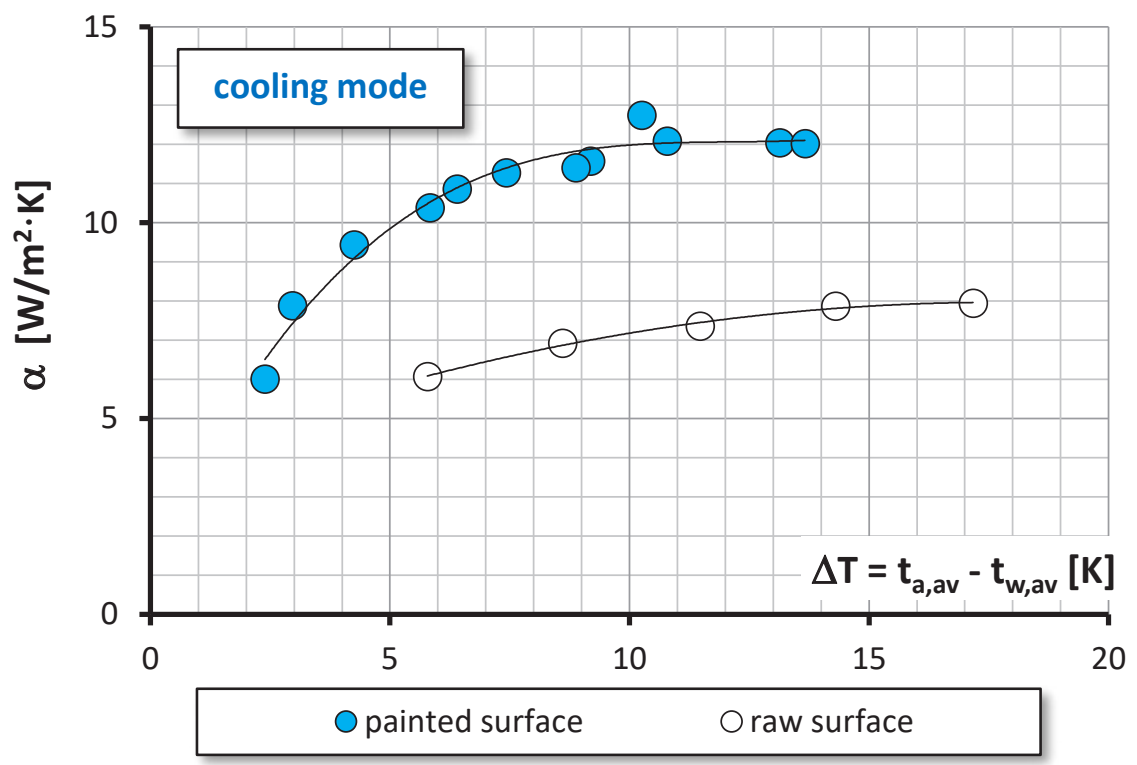

Fig. 5. The total heat transfer coefficient for cooling mode as a function of the temperature difference between surface and air.

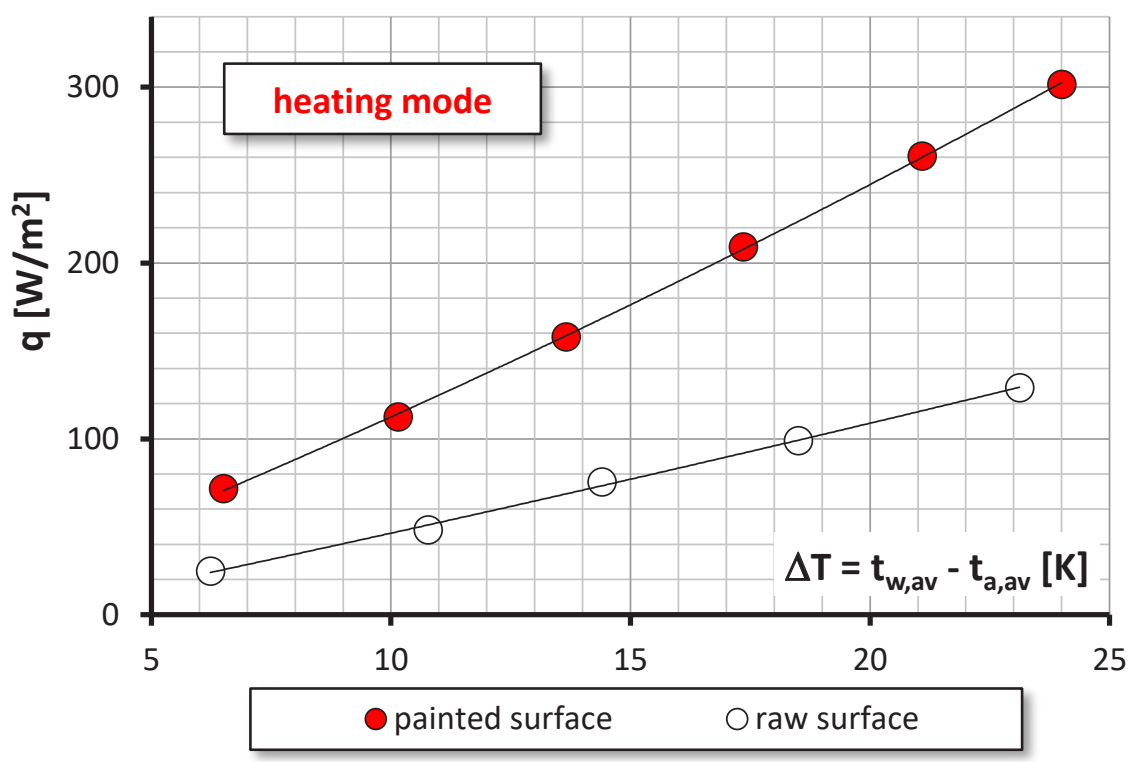

Fig. 6. The specific thermal power of the surface in the heating mode. 


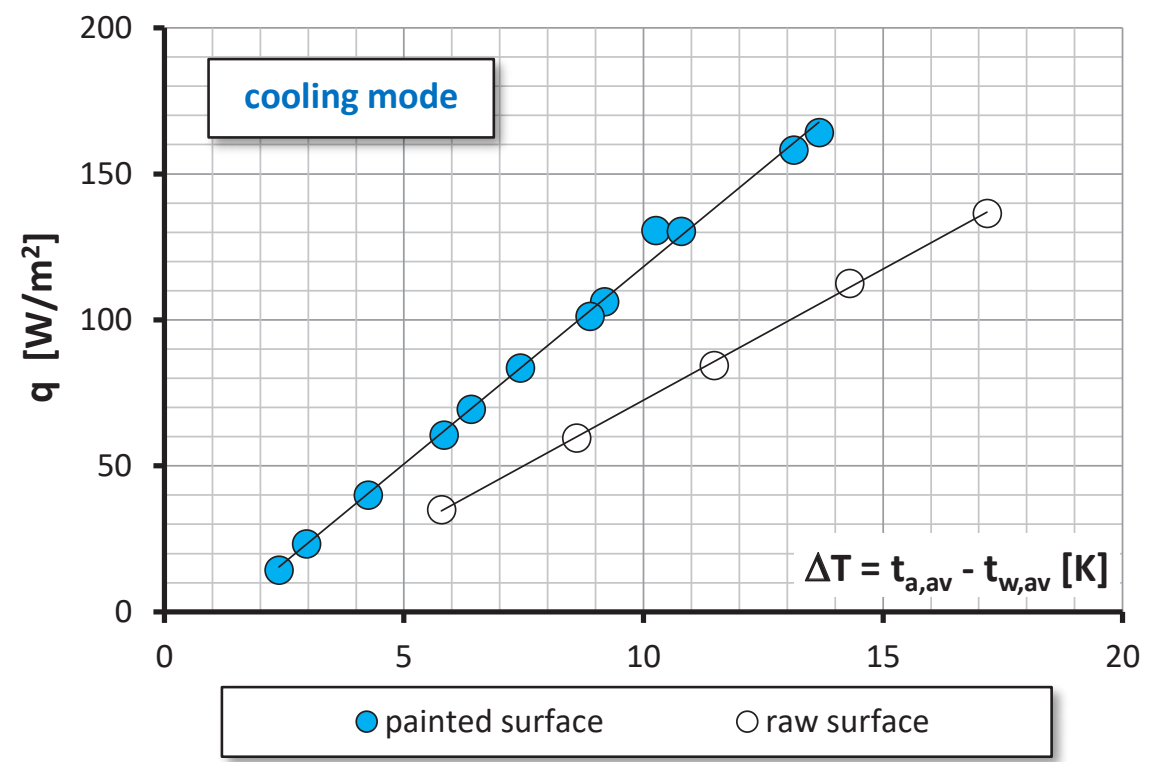

Fig. 7. The specific thermal power of the surface in the cooling mode.

\section{Conclusions}

The experimental investigation results presented in this paper led to the following conclusions:

- heating performance of ceiling-oriented surface is lower than the cooling performance what agrees with the literature data,

- covering the metal surface with paint increases the heat transfer through radiation and as a result increases the thermal performance,

- the heating power of the black-painted ceiling surface is 2.3 to 2.8 times higher than the unpainted one,

- the cooling power of the black-painted ceiling surface is 1.5 to 1.7 times higher than the unpainted one,

- the large percentage increase in the heating power of the ceiling surface caused by its painting results from the relatively small value of the convective component in ceiling heating,

- the use of paint of a color other than black will increase the heating and cooling performance of the surface in a similar way as in the case of covering with black paint, because the emissivity of typical paints are almost equal $(\varepsilon=0.90-0.95)$. 


\section{References}

1. Ł. Amanowicz, E. Szczechowiak, COW 48, 72-78 (2017)

2. Ł. Amanowicz, J. Wojtkowiak, Therm. Sci. and Eng. Prog. 5, 44-49 (2018)

3. K. Chmielewski, Ł. Amanowicz, Rynek Instal. 5, 76-80 (2017)

4. J. Wojtkowiak, Ł. Amanowicz, COW. 47, 413-417 (2016)

5. Ł. Amanowicz, Doświadczalne charakterystyki przeptywowe powietrznych wielorurowych gruntowych wymienników ciepła (Wyd. Pol. Pozn., Poznań, 2016)

6. Ł. Amanowicz, J. Wojtkowiak, COW 41, 208-212,220 (2010)

7. Ł. Amanowicz, J. Wojtkowiak, XIII International Conference Air \& Heat-Water and Energy 2011, Wrocław-Kudowa

8. Ł. Amanowicz, J. Wojtkowiak, Found. of Civil and Environ. Eng. 15, 5-18 (2012)

9. Ł. Amanowicz, J. Wojtkowiak, $11^{\text {th }}$ REHVA world Congress CLIMA 2013, Prague

10. Ł. Amanowicz, J. Wojtkowiak, Rynek Instal. 2, 70-73 (2014)

11. Ł. Amanowicz, J. Wojtkowiak, COW 48, 413-417 (2017) 